doi:10.4149/neo_2017_601

\title{
Exosomes of human mesenchymal stem/stromal/medicinal signaling cells
}

\author{
Minireview
}

U. ALTANEROVA ${ }^{1}$, J. JAKUBECHOVA 1 , V. REPISKA ${ }^{2}$, C. ALTANER ${ }^{1,3, *}$

${ }^{1}$ St. Elisabeth Cancer Institute, Stem Cell Preparation Department, Bratislava, Slovakia; ${ }^{2}$ Institute of Medical Biology, Genetics and Clinical Genetics, Faculty of Medicine, Comenius University in Bratislava, Slovakia; ${ }^{3}$ Cancer Research Institute, BMC, Slovak Academy of Sciences, Bratislava, Slovakia

${ }^{*}$ Correspondence: exonalt@savba.sk

Received June 5, 2017 / Accepted August 16, 2017

\begin{abstract}
In this review, we intend to explore the potential therapeutic effects of exosomes released from mesenchymal stem/stromal cells (MSCs). MSCs gained credibility as a therapeutic tool due to their potential to differentiate into many cell types like osteoblasts, chondrocytes, adipocytes, muscular, endothelial, cardiovascular, and neurogenic cells. They possess potent wound healing activity due to their immunosuppressive and anti-inflammatory properties. MSCs are tested in large number of clinical trials for treatment of diseases, which do not have adequate therapy at present. MSCs engineered to express suicide genes in preclinical studies have shown promising tumor targeting therapeutic tool for malignancies difficulty treatable at present. It has been increasingly observed in many different kinds of regenerative medicine and in MSCs mediated prodrug gene therapy for cancer that the intravenously administered of MSCs did not necessarily engraft at the site of injury or tumor. The therapeutic effect was exerted mainly through a paracrine action of rich secretome released from the cells. The main biocomponent of secretome are exosomes - naturally occurring membrane nanoparticles of 30-120 nm in diameter that mediate intercellular communication by delivering biomolecules like mRNA, miRNA into recipient cells. These nanosized exosomes derived from MSCs promise to be a new and valuable therapeutic strategy in regenerative medicine and cancer therapy compared with transplanted exogenous MSCs. Advantage of nanosized exosomes compared with administration of exogenous MSCs is multiple. Exosomes are easier to preserve and be transferred, have lower immunogenicity and therefore are safer for therapeutic administration.
\end{abstract}

Key words: mesenchymal stem cells, exosomes, conditional medium, secretome, regenerative medicine, yCD::UPRT gene, prodrug gene cancer therapy, yCD::UPRT exosomes

Mesenchymal stem cells (MSCs) were assigned as cells responsible for repair and maintenance of used and damaged tissues keeping cellular homeostasis in the body. They are frequently called mesenchymal stromal cells because they are supporting other stem cells in tissues, for example in the bone marrow by forming stroma support for hematopoietic stem cells. Originally they were thought to be stem cells based on their ability to differentiate to a variety of cell types in vitro. MSCs were regarded multipotent having the potential to differentiate into many cell types. The definition of MSCs is up to now based on an internationally approved set of criteria including plastic adherence, tri-lineage in vitro differentiation ability and expression of various MSC surface markers [1]. MSCs gained credibility as a therapeutic tool due of their potential to differentiate into many cell types like osteoblasts, chondrocytes, adipocytes, muscular, endothelial, cardiovascular, and neurogenic cells. In addition to their direct role in tissue regeneration, MSCs have potent wound healing activity due to their immunosuppressive and anti-inflammatory properties. MSCs can be isolated and easy expanded from tissues like bone marrow, adipose tissue, umbilical cord, placenta, dental pulp and others. Very wide range of therapeutic applications are tested in large number of clinical trials for treatment of diseases, which do not have adequate therapy at present. MSCs clinical studies are in progress around the world for clinical conditions such as multiple sclerosis, amyotrophic lateral sclerosis, stroke, acute and chronic heart failure, rheumatoid arthritis and osteoarthritis, Crohn's disease, kidney or liver chronic disease, sepsis, spinal cord contusions, critical limb ischemia and others. As of May 2017, the public clinical 


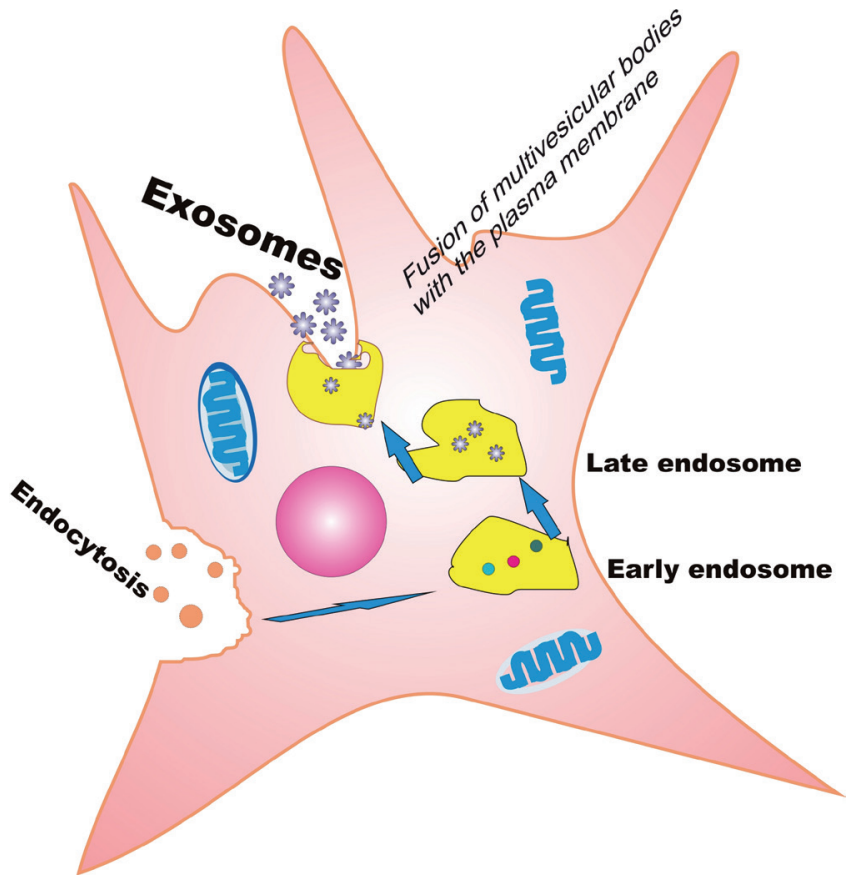

Figure 1. Schematic picture depicting MSCs exosome formation. Exosomes are secreted by MSCs upon fusion of multivesicular bodies with the plasma membrane. Their cargo contains functional biomolecules like mRNA, miRNA, DNA and proteins. Besides that, they secrete cellular waste. This behavior is used for therapeutic purposes, like for easier delivery of drugs or therapeutic gene modified MSCs release exosomes with mRNA of relevant gene. The figure is not drawn to scale.

trials database (as shown on http://www.clinicaltrials.gov with "mesenchymal stem cells" used as the search term) showed 719 clinical trials related to MSCs involvement [2].

\section{Reparatory process is induced by action of MSCs' secretome}

It has been increasingly observed in many different kinds of regenerative medicine that the transplanted MSCs did not necessarily engraft and differentiate at the site of injury. When MSCs were intravenously administered, up to $80 \%$ of the injected cells were found in the lungs within a few minutes after injection with a half-life of about 24 hours and practically complete disappearance after 4 days in animal model $[3,4]$. The observed biodistribution patterns were confirmed by studies in humans. In patients with mammary carcinoma [5], the therapeutic effect was exerted by inducing the endogenous natural reparatory processes with noticeable improvement 6-8 weeks later. This was found not compatible with direct action of transplanted cells in tissue regeneration as it was believed previously. MSCs biodistribution data confirmed the importance of secreted factors from the cells into conditional medium (CM), some acting mainly through a paracrine action. It has been recognized that MSCs release a rich secretome containing massive amounts of cytokines, chemokines and growth factors, together with extracellular exosomes that might be responsible at least to some degree for transfer of regulatory gene products needed for the paracrine and endocrine induction of reparatory processes. It is now well recognized that exosomes from various cells including tumor cells because of their easy cells internalization can act in trans-tissue manner [6]. MSCs exosomes act mainly as tissue stromal support and help maintain tissue homeostasis, Timmers et al. have shown the reduction of myocardial infarct size by human MSCs conditioned medium (CM) administered intravenously and intracoronary in a porcine model at first [7]. It was proved that purified exosomes were responsible for the reduced infarct size in an animal model of myocardial ischemia/reperfusion injury [8]. Therefore, MSCs act through paracrine mechanisms to trigger regenerative processes [9]. The main component within the secretome are exosomes, which transfer bioactive molecules (mRNAs and microRNAs) as a cargo between cells $[10,11]$. It was suggested by Caplan $[12,13]$ that the name of MSCs should be changed to Medicinal Signalling Cells to more accurately reflect the fact that these cells home in on sites of injury or disease. These cells make therapeutic drugs in situ by secretion of bioactive factors that suppress the local immune system, inhibit scar formation and apoptosis, enhance angiogenesis, and stimulate mitosis and differentiation of tissue-intrinsic reparative stem cells. It is, indeed the combined action of MSCs's secretome and secreted exosomes triggering the patient's own site-specific and tissue-specific resident stem cells to construct a new tissue and/or repair the damaged one. The content of exosome's cargo, specifically mRNA, in the induced reparatory process plays an important role.

\section{Nanoparticles released by MSCs}

Most cell types release extracellular vesicles as membranesurrounded structures. Three main classes, exosomes (30-120 $\mathrm{nm})$, shedding microvesicles (100-1000 nm) and apoptotic bodies (50-4000 $\mathrm{nm}$ ) have been recognized. Exosomes, unlike the other extracellular vesicles are the only secreted vesicles to have an endosomal biogenesis [14]. They are micro membrane vesicles that possess several properties related to the stabilization of cellular homeostasis. Originally, they were recognized as nanoparticles secreting cellular waste [15] and this behavior can be used for therapeutic purpose [16]. MSCs exosomes are useful tools for easier delivery of drugs [17]. We have proved that they can include ferromagnetic material into their cargo forming thus nanoparticles suitable for hyperthermia tumor therapy [unpublished]. Exosomes are secreted by most cell types upon fusion of multivesicular bodies with the plasma membrane. Schematic picture of exosome formation is depicted in Figure 1. Intercellular communication mediated by transfer of functional biomolecules like mRNA, miRNA, DNA and proteins is the main function of exosomes [18]. Ability to transfer gene informative molecules especially exosomes released from MSCs is the basis of many applica- 
tions in regenerative medicine. Exosomes of MSCs together with their secretome have been identified as tools behind the immunomodulatory effects [19-21], induction of angiogenesis [22-25], cell proliferation [26], antiapoptotic effect [27, 28] and anti-inflammatory effect [29]. Experimental data suggest that MSCs exosomes might be therapeutically useful in such lethal medical complications as the acute kidney injury [30]. Despite the exact mechanism of in vivo action of exogenously administered stem/stromal mesenchymal cells-derived exosomes are not fully elucidated [reviewed in [31], several clinical studies with MSCs extracellular vesicles (Evs) are in progress. Analysis of results of the older phase I clinical trials of exosomes-based therapies revealed that no serious acute events have been associated with EVs administration [32, 33].

\section{MSCs induced mechanisms of regenerative process}

The involvement of MSCs exosomes and components released from their cargo in the recipient cells rest in modulating multiple cellular pathways. The activation of regenerative process is rather a complex mechanism. Differential expression analysis in porcine adipose tissue-derived MSCs revealed 4 miRNAs, 255 mRNAs, and 277 proteins enriched in exosomes versus cells [34]. Perhaps the interactions between mRNA and miRNA targeting transcription factors and proteins capable of modifying multiple cellular pathways may be a selective mechanism driving so many various MSCs-based repairs. In addition, MSCs exosomes may in the inflammation microenvironment support extracellular matrix remodeling and angiogenesis. Regenerative medicine experience suggests that MSCs are naturally found as pericytes localized on vein walls of the vascularized tissues. In order to heal injured tissues without scarring, MSCs are released at sites of the injury, where they secrete large quantities of bioactive factors and exosomes that are immunomodulatory thus preventing autoimmunity and inhibit lymphocyte surveillance of the injured tissue. The exosomes in concord with MSCs secretome target tissue intrinsic progenitor cells. Consequently, ischemia-caused apoptosis is prevented, and angiogenesis is stimulated. Healing process continues through cell division of the natural intrinsic regenerative cells [12]. The consecutive steps in wound healing process triggered by presumptive coordinated actions of MSCs secretome through paracrine/autocrine/endocrine manner are listed in Tablel. To the human MSCs healing activity is contributing the antibacterial effect mediated in part by the secretion of human cathelicidin hCAP-18/LL-37 [35]. MSCs exosomes are partly involved in antibacterial activity through the expression of keratinocyte growth factor by mRNA in the site of injury [36]. Recently it was reported that MSCs can communicate with their microenvironment through bidirectional exchange of mitochondria. The apoptosis of damaged cells was prevented through delivery of their own mitochondria [37]. It was established that MSCs use tunneling nanotubes as the means to transfer mitochondria to injured cell [38].

\section{Tumor trophic behavior of MSCs engineered to express suicide genes}

MSCs recognize tumor as a not-healing wound [39]. MSCs migrate to it and frequently became a part of tumor stroma with consequences like tumor growth modification, confer of drug resistance and transition to tumor associated fibroblasts $[40,41]$. We used MSCs tumor trophic behavior to develop two prodrug suicide gene therapy systems for cancer mediated by MSCs. We have shown that MSCs transduced with yeast cytosinedeaminase::uracil phosphoribosyltransferase gene (yCD::UPRT) by retroviral infection can convert nontoxic 5-fluorocytosine (5-FC) to the effective cytotoxic compound 5-fluorouracil [42]. MSCs engineered to express thymidine kinase of Herpes simplex virus is the second therapeutic system we have developed [43]. In this system the prodrug ganciclovir is converted by cellular enzymes to ganciclovir triphosphate that inhibits DNA synthesis of recipient cells. Suicide gene transduced MSCs have the advantage of being stable with an effective production of the prodrug-converting enzyme under the control of a strong retroviral promoter from the DNA provirus integrated into the cellular DNA. Vector construction allows for antibiotic selection of the transduced cells yielding pure populations of transduced cells [44]. Elimination of non-transduced cells is rather important, MSCs can potentially support tumor cell growth by secreted

Table 1. MSCs involvement in natural wound healing

\begin{tabular}{lll}
\hline & The prominent paracrine factors involved: & Reference \\
\hline $\begin{array}{l}\text { Pericytes present on the walls of veins of vasculature are activated } \\
\text { to act as MSCs }\end{array}$ & Activation of platelet-derived growth factor-beta receptor \\
\hline MSC-secretome suppress the local immune system and apoptosis & Prostaglandin E2 and IL-6 \\
\hline Secreted bioactive factors inhibit fibrosis (scar formation) & $\begin{array}{l}\text { Platelet-derived growth factor, insulin-like growth factor-1, IL-8, } \\
\text { hepatocyte growth factor }\end{array}$ \\
\hline Angiogenesis is enhanced & $\begin{array}{l}\text { Vascular endothelial growth factor (VEGF), hepatocyte growth } \\
\text { factor (HGF), monocyte chemotactic protein-1 (MCP-1), } \\
\text { angiopoietin-1. }\end{array}$ \\
\hline MSCs exosomes internalize cells surrounding wound & \\
\hline
\end{tabular}


cytokines and growth factors. The attractiveness of these therapeutic systems lies in the conversion of a not toxic prodrug to a cytostatic drug directly within the tumor mass, thus avoiding systemic toxicity [45]. In addition, the genetically modified MSCs designated as Therapeutic Stem cells (ThSc) have sustained tumor-tropism and the prodrug administration not only eliminates tumor cells, but consequently kills the more resistant therapeutic cells as well, thereby eliminating them from the host [46]. Compared with conventional chemotherapy, yCD::UPRT/5-FC MSCs mediated therapeutic system exhibited no significant systemic adverse effects.

\section{MSCs transduced with yCD::UPRT gene release exosomes with mRNA of the suicide gene in their cargo}

In preclinical studies with human melanoma cells [46], prostate cancer cells [47] implanted subcutaneously to immunocompromised nude mice and with intravenously injected $\mathrm{ThSc}$ significant tumor growth inhibition was observed. These data were not compatible with the known biodistribution of intravenously administered cells, where 80 percent of MSCs end in lungs [3]. Biodistribution measurements of intravenously injected labeled MSCs revealed that cells are immediately entrapped in lung tissue and then clear to the liver within one day [48]. The high tumor inhibiting activity of intravenously administered ThSc was explained when we found that suicide gene transduced MSCs release exosomes with mRNA of suicide gene in their cargo $[49,50]$. Analysis of CM from yCD::UPRT-AT-MSCs revealed the presence of exosomes with mRNA of the yCD::UPRT gene and free translated enzyme. We have proved that all yCD::UPRT gene transduced human MSCs derived from various tissues like adipose, bone mar- row, dental pulp, umbilical cord and menstrual blood derived endometrial regenerative cells release exosomes with mRNA of $y C D:: U P R T$ gene into CM. Thus the efficacy of prodrug gene therapy for cancer mediated by MSCs in the presence of 5 -FC was found to act not only through bystander effect, but is potentiated by internalized exosomes as well. The exosomes inhibit growth of human tumor cell lines and human primary glioblastoma cells in a dose dependent manner in vitro. Growth of tumor cells with $\mathrm{CM}$ additions with and without prodrug 5 -FC monitored in real time was found very informative. It revealed that for translation of suicide protein from mRNA delivered by exosomes present in the CM was needed about 30 hours. In addition, the tumor cell growth comparison of cells influenced by control medium versus control medium with $\mathrm{CM}$ additions has shown the growth stimulation caused by secretome in a dose dependent manner. Tumor cell killing by 5 -fluorouracil formed intracellulary form the prodrug was a dose dependent manner as well (Figure 2). Therapeutic exosome involvement was likely responsive for curative therapy of rat glioblastoma treated with intracerebral administration of human yCDy-UPRT cells [51]. Accumulating evidence indicates that cancer therapy using MSCs exosomes have multiple advantages over cell therapy. CM or exosomes are stable after intravenous administration and exhibit a superior safety profile. Since MSCs have the remarkable tendency to home to tumors, exosomes produced by MSCs may retain the homing properties of their parent cells. Dental pulp derived MSCs being of neural crest-derived cells might serve as an example. We have recently shown that dental pulp-derived MSCs can migrate to intracerebral glioblastomas after intranasal administration [50]. Number of studies of regenerative medicine field has shown that nanoparticles produced by MSCs exert their therapeutic effects in several diseases, suggesting that MSC-derived

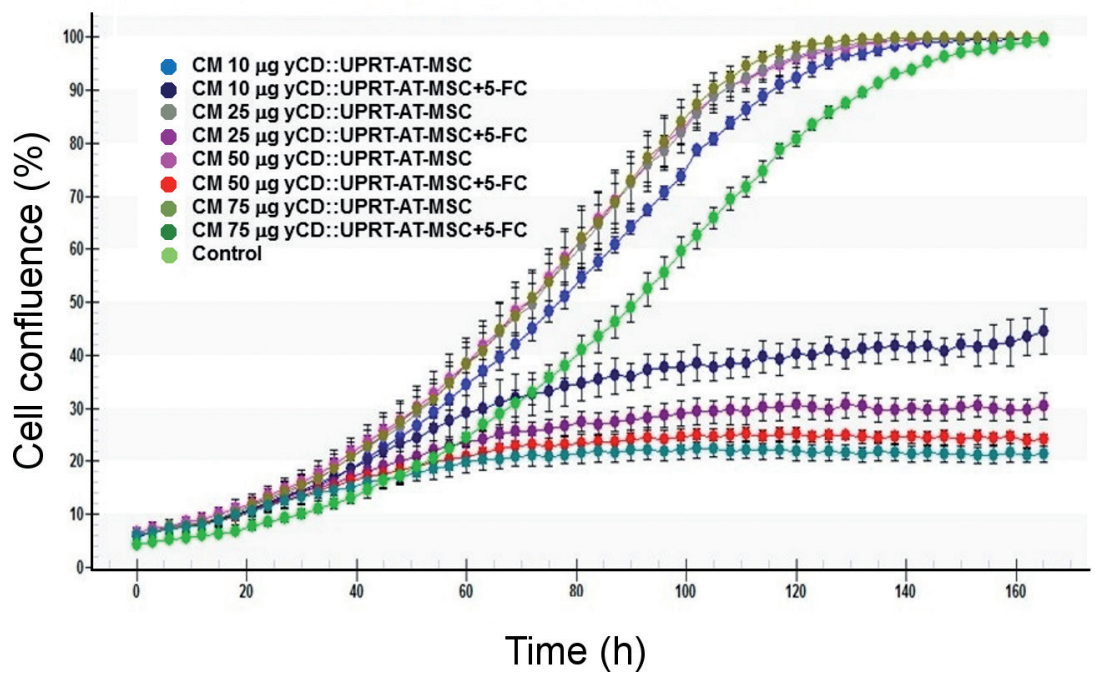

Figure 2. Exosomes in conditional medium kill prostate cancer cells PC3 in a dose dependent manner. Growth curves of PC3 cells treated with CM from yCD::UPRT-AT-MSCs in presence and/or absence of 5-FC. PC3 cells $\left(3 \times 10^{3}\right)$ were plated in wells of the 96 well plate. Next day, indicated $\mu \mathrm{g}$ of CM were added to growth medium in each well either with prodrug 5-FC or without 5-FC. The course of growth/inhibition was monitored by the Incucyte system. 
nanoparticles - exosomes may be a promising alternative to cell therapy. MSCs engineered to express suicide genes release exosomes. Their cargo contains suicide gene mRNA. Internalization of these exosomes in recipient cancer cells was found responsible for the growth inhibiting effect. Thus the prodrug suicide gene therapy mediated by MSCs is converted to the prodrug cancer suicide gene therapy mediated by therapeutic MSC exosomes. Nanoparticles released from tumor cells possess many diverse biological functions. Tumor cells secreted exosomes might support neoplastic growth, invasion, and metastasis [52]. Moreover; exosomes from human lung-, liverand brain-tropic tumor cells are organ specific, preferentially penetrate resident cells at their predicted destination [53]. The tumor-derived exosomes up taken by organ-specific cells prepare the pre-metastatic niche $[53,54]$. All these findings might have application in prodrug gene cancer therapy mediated by exosomes targeted to organ specific metastases.

Advantage of nanosized exosomes compared with administration of exogenous MSCs is multiple. Exosomes are easier to preserve and transferred have lower immunogenicity and therefore are safer for therapeutic administration.

Acknowledgments: This study was supported by a grant awarded to CA by the Slovak League against Cancer.

\section{References}

[1] DOMINICI M, LE BLANC K, MUELLER I, SLAPER-CORTENBACH I, MARINI F et al. Minimal criteria for defining multipotent mesenchymal stromal cells. The International Society for Cellular Therapy position statement. Cytotherapy 2006; 8: 315-317. https://doi. org/10.1080/14653240600855905

[2] ClinicalTrials.gov. A service of the U.S. National Institutes of Health. Available from: https://clinicaltrials.gov/ct2/show. Access date 25-05-2017.

[3] LEIBACHER J, HENSCHLER R. Biodistribution, migration and homing of systemically applied mesenchymal stem/ stromal cells. Stem Cell Res Ther 2016; 7: 7. https://doi. org/10.1186/s13287-015-0271-2

[4] LEE RH, PULIN AA, SEO MJ, KOTA DJ, YLOSTALO J et al. Intravenous hMSCs improve myocardial infarction in mice because cells embolized in lung are activated to secrete the anti-inflammatory protein TSG-6. Cell Stem Cell 2009; 5: 54-63. https://doi.org/10.1016/j.stem.2009.05.003

[5] KOC ON, GERSON SL, COOPER BW, DYHOUSE SM, HAYNESWORTH SE et al. Rapid hematopoietic recovery after coinfusion of autologous-blood stem cells and cultureexpanded marrow mesenchymal stem cells in advanced breast cancer patients receiving high-dose chemotherapy. J Clin Oncol 2000; 18: 307-316. https://doi.org/10.1200/ ICO.2000.18.2.307

[6] ZDURIENCIKOVA M, GRONESOVA P, CHOLUJOVA D, SEDLAK J. Potential biomarkers of exosomal cargo in endocrine signaling. Endocr Regul 2015;49: 141-150. https://doi. org/10.4149/endo $2015 \quad 03 \quad 141$
[7] TIMMERS L, LIM SK, ARSLAN F, ARMSTRONG JS, HOEFER IE et al. Reduction of myocardial infarct size by human mesenchymal stem cell conditioned medium. Stem Cell Res 2007; 1: 129-137. https://doi.org/10.1016/j.scr.2008.02.002

[8] LAI RC, ARSLAN F, LEE MM, SZE NS, CHOO A et al. Exosome secreted by MSC reduces myocardial ischemia/ reperfusion injury. Stem Cell Res 2010; 4: 214-222. https:// doi.org/10.1016/j.scr.2009.12.003

[9] RANI S, RYAN AE, GRIFFIN MD, RITTER T. Mesenchymal Stem Cell-derived Extracellular Vesicles: Toward Cell-free Therapeutic Applications. Mol Ther 2015; 23: 812-823. https:// doi.org/10.1038/mt.2015.44

[10] CHEN TS, LAI RC, LEE MM, CHOO SB, LEE CN et al. Mesenchymal stem cell secretes microparticles enriched in pre-microRNAs. Nucleic Acids Res 2010; 38: 215-224. https:// doi.org/10.1093/nar/gkp857

[11] BAGLIO SR, ROOIJERS K, KOPPERS-LALIC D, VERWEIJ FJ, PEREZ LANZON $M$ et al. Human bone marrow- and adipose-mesenchymal stem cells secrete exosomes enriched in distinctive miRNA and tRNA species. Stem Cell Res Ther 2015; 6: 127. https://doi.org/10.1186/s13287-015-0116-Z

[12] CAPLAN AI, DENNIS JE. Mesenchymal stem cells as trophic mediators. J Cell Biochem 2006; 98:1076-1084. https://doi. org/10.1002/jcb.20886

[13] CAPLAN AI. Mesenchymal Stem Cells: Time to Change the Name! Stem Cells Transl Med 2017; 6: 1445-1451. https://doi. org/10.1002/sctm.17-0051

[14] TAN SS, YIN Y, LEE T, LAI RC, YEO RW et al. Therapeutic MSC exosomes are derived from lipid raft microdomains in the plasma membrane. J Extracell Vesicles 2013; 2: 22614. https://doi.org/10.3402/jev.v2i0.22614

[15] TRAMS EG, LAUTER CJ, SALEM N JR, HEINE U. Exfoliation of membrane ecto-enzymes in the form of microvesicles. Biochim Biophys Acta 1981; 645: 63-70. https://doi. org/10.1016/0005-2736(81)90512-5

[16] GYORGY B, HUNG ME, BREAKEFIELD XO, LEONARD JN. Therapeutic Applications of Extracellular Vesicles: Clinical Promise and Open Questions. Annu Rev Pharmacol Toxicol 2015; 55: 439-464. https://doi.org/10.1146/annurev-pharmtox-010814-124630

[17] YEO RW, LAI RC, ZHANG B, TAN SS, YIN Y et al. Mesenchymal stem cell: An efficient mass producer of exosomes for drug delivery. Adv Drug Deliv Rev 2013; 65: 336-341. https:// doi.org/10.1016/j.addr.2012.07.001

[18] VALADI H, EKSTROM K, BOSSIOS A, SJOSTRAND M, LEE $\mathrm{JJ}$ et al. Exosome mediated transfer of mRNAs and microRNAs is a novel mechanism of genetic exchange between cells. Nat Cell Biol 2007; 9: 654-659. https://doi.org/10.1038/ncb1596

[19] ZHANG B, YIN Y, LAI RC, TAN SS, CHOO BB et al. Mesenchymal stem cells secrete immunologically active exosomes. Stem Cells Dev 2014; 23: 1233-1244. https://doi.org/10.1089/ $\underline{\text { scd.2013.0479 }}$

[20] BLAZQUEZ R, SANCHEZ-MARGALLO FM, DE LA ROSA $\mathrm{O}$, DALEMANS W, ALVAREZ V et al. Immunomodulatory potential of human adipose mesenchymal stem cells derived exosomes on in vitro stimulated T cells. Front Immunol 2014; 5: 556. https://doi.org/10.3389/fimmu.2014.00556 
[21] CASADO JG, BLAZQUEZ R, VELA FJ, ALVAREZ V, TARAZONA R et al. Mesenchymal Stem Cell-Derived Exosomes: Immunomodulatory Evaluation in an Antigen-Induced Synovitis Porcine Model. Front Vet Sci 2017; 4: 39. https:// doi.org/10.3389/fvets.2017.00039

[22] BIAN S, ZHANG L, DUAN L, WANG X, MIN Y et al. Extracellular vesicles derived from human bone marrow mesenchymal stem cells promote angiogenesis in a rat myocardial infarction model. J Mol Med (Berl) 2014; 92: 387-397. https://doi. org/10.1007/s00109-013-1110-5

[23] RANGHINO A, CANTALUPPI V, GRANGE C, VITILLO L, FOP F et al. Endothelial progenitor cell-derived microvesicles improve neovascularization in a murine model of hindlimb ischemia. Int J Immunopathol Pharmacol 2012; 25: 75-85. https://doi.org/10.1177/039463201202500110

[24] SAHOO S, KLYCHKO E, THORNE T, MISENER S, SCHULTZ KM et al. Exosomes from human CD34(+) stem cells mediate their proangiogenic paracrine activity. Circ Res 2011; 109: 724-728. https://doi.org/10.1161/CIRCRESAHA.111.253286

[25] CANTALUPPI V, BIANCONE L, FIGLIOLINI F, BELTRAMO S, MEDICA D et al. Microvesicles derived from endothelial progenitor cells enhance neoangiogenesis of human pancreatic islets. Cell Transplant 2012; 21: 1305-1320. https://doi.org/10.3727/096368911X627534

[26] SHABBIR A, COX A, RODRIGUEZ-MENOCAL L, SALGADO M, VAN BADIAVAS E. Mesenchymal stem cell exosomes induce proliferation and migration of normal and chronic wound fibroblasts, and enhance angiogenesis in vitro. Stem Cells Dev 2015; 24: 1635-1647. https://doi.org/10.1089/ scd.2014.0316

[27] YU B, KIM HW, GONG M, WANG J, MILLARD RW et al. Exosomes secreted from GATA-4 overexpressing mesenchymal stem cells serve as a reservoir of anti-apoptotic microRNAs for cardioprotection. Int J Cardiol 2015; 182:349-360. https:// doi.org/10.1016/j.ijcard.2014.12.043

[28] ZHOU Y, XU H, XU W, WANG B, WU H et al. Exosomes released by human umbilical cord mesenchymal stem cells protect against cisplatin-induced renal oxidative stress and apoptosis in vivo and in vitro. Stem Cell Res Ther 2013; 4: 34. https://doi.org/10.1186/scrt194

[29] TENG X, CHEN L, CHEN W, YANG J, YANG Z et al. Mesenchymal stem cell-derived exosomes improve the microenvironment of infarcted myocardium contributing to angiogenesis and anti-inflammation. Cell Physiol Biochem 2015; 37: 2415-2424. https://doi.org/10.1159/000438594

[30] BRUNO S, GRANGE C,COLLINO F, DEREGIBUS MC, CANTALUPPI $\mathrm{V}$ et al. Microvesicles derived from mesenchymal stem cells enhance survival in a lethal model of acute kidney injury, PLoS One 2012; 7: e33115. https://doi. org/10.1371/journal.pone.0033115

[31] DI ROCCO G, BALDARI S, TOIETTA G. Towards Therapeutic Delivery of Extracellular Vesicles: Strategies for In Vivo Tracking and Biodistribution Analysis. Stem Cells Int 2016; 2016: 5029619. https://doi.org/10.1155/2016/5029619

[32] OHNO S, DRUMMEN GP, KURODA M. Focus on extracellular vesicles: development of extracellular vesicle-based therapeutic systems. Int J Mol Sci 2016; 17: 172. https://doi. org/10.3390/ijms17020172

[33] LENER T, GIMONA M, AIGNER L, BORGER V, BUZAS E et al. Applying extracellular vesicles based therapeutics in clinical trials - an ISEV position paper. J Extracell Vesicles 2015; 4: 30087. https://doi.org/10.3402/jev.v4.30087

[34] EIRIN A, ZHU XY, PURANIK AS, WOOLLARD JR, TANG $\mathrm{H}$ et al. Integrated transcriptomic and proteomic analysis of the molecular cargo of extracellular vesicles derived from porcine adipose tissue-derived mesenchymal stem cells. PLoS One 2017: 12: e0174303. https://doi.org/10.1371/journal. pone. 0174303

[35] KRASNODEMBSKAYA A, SONG Y, FANG X, GUPTA N, SERIKOV V et al. Antibacterial effect of human mesenchymal stem cells is mediated in part from secretion of the antimicrobial peptide LL-37. Stem Cells 2010; 28: 2229-2238. https:// doi.org/10.1002/stem.544

[36] ZHU YG, FENG XM, ABBOTT J, FANG XH, HAO Q et al. Human mesenchymal stem cell microvesicles for treatment of Escherichia coli endotoxin-induced acute lung injury in mice. Stem Cells 2014; 32: 116-125. https://doi.org/10.1002/ $\underline{\text { stem. } 1504}$

[37] MAHROUF-YORGOV M, AUGEUL L, CROLA DA SILVA C, JOURDAN M, RIGOLET M et al. Mesenchymal stem cells sense mitochondria released from damaged cells as danger signals to activate their rescue properties. Cell Death Differ 2017; 24: 1224-1238. https://doi.org/10.1038/cdd.2017.51

[38] JACKSON MV, KRASNODEMBSKAYA AD. Analysis of Mitochondrial Transfer in Direct Co-cultures of Human Monocyte-derived Macrophages (MDM) and Mesenchymal Stem Cells (MSC). Bio Protoc 2017; 7: e2255. https://doi. org/10.21769/BioProtoc. 2255

[39] DVORAK HF. Tumors: wound that do not heal. Similarities between tumor stroma generation and wound healing. N Engl J Med 1986; 315: 1650-1659. https://doi.org/10.1056/ NEJM198612253152606

[40] SPAETH EL, DEMBINSKI JL, SASSER AK, WATSON KA. KLOPP B et al. Mesenchymal stem cell transition to tumorassociated fibroblasts contributes to fibrovascular network expansion and tumor progression. PLoS One 2009; 4: e4992. https://doi.org/10.1371/journal.pone.0004992

[41] BARCELLOS-DE-SOUZA P, COMITO G, PONS-SEGURA C, TADDEI ML, GORI V et al. Mesenchymal Stem Cells are Recruited and Activated into Carcinoma-Associated Fibroblasts by Prostate Cancer Microenvironment-Derived TGF- $\beta 1$. Stem Cells 2016; 34: 2536-2547. https://doi. org/10.1002/stem.2412

[42] KUCEROVA L, ALTANEROVA V, MATUSKOVA M, TYCIAKOVA S, ALTANER C. Adipose tissue-derived human mesenchymal stem cells mediated prodrug cancer gene therapy. Cancer Res 2007; 67: 6304-6313. https://doi. org/10.1158/0008-5472.CAN-06-4024

[43] MATUSKOVA M, HLUBINOVA K, PASTORAKOVA A, HUNAKOVA L, ALTANEROVA V et al. HSV-tk expressing mesenchymal stem cells exert bystander effect on human glioblastoma cells. Cancer Lett 2010; 290: 58-67. https://doi. org/10.1016/j.canlet.2009.08.028 
[44] ALTANER C. Prodrug cancer gene therapy. Cancer Lett 2008; 270: 191-201. https://doi.org/10.1016/j.canlet.2008.04.023

[45] CIHOVA M, ALTANEROVA V, ALTANER C. Stem cell based cancer gene therapy. Mol Pharm 2011; 8: 1480-1487. https:// doi.org/10.1021/mp200151a

[46] KUCEROVA L, MATUSKOVA M, PASTORAKOVA A, TYCIAKOVA S, JAKUBIKOVA J et al. Cytosine deaminase expressing human mesenchymal stem cells mediated tumour regression in melanoma bearing mice. J Gene Med 2008; 10 : 1071-1082. https://doi.org/10.1002/jgm.1239

[47] CAVARRETTA IT, ALTANEROVA V, MATUSKOVA M, KUCEROVA L, CULIG Z et al. Adipose tissue-derived mesenchymal stem cells expressing prodrug-converting enzyme inhibit human prostate tumor growth. Mol Ther 2010; 18 : 223-231. https://doi.org/10.1038/mt.2009.237

[48] ZHENG B, VON SEE MP, YU E, GUNEL B, LU K et al. Quantitative Magnetic Particle Imaging Monitors the Transplantation, Biodistribution, and Clearance of Stem Cells In Vivo. Theranostics 2016; 6: 291-301. https://doi.org/10.7150/thno.13728

[49] ALTANER C. Prodrug gene therapy for cancer mediated by mesenchymal stem/stromal cells engineered to express yeast cytosinedeaminase::uracil phosphoribosyltransferase. J Stem Cell Res Ther 2015; 5: 1000264. https://doi.org/10.4172/21577633.1000264

[50] ALTANEROVA U, BENEJOVA K, ALTANEROVA V, TYCIAKOVA S, RYCHLY B et al. Dental pulp mesenchymal stem/stromal cells labeled with iron sucrose release exosomes and cells applied intra-nasally migrate to intracerebral glioblastoma. Neoplasma 2016; 63: 925-933. https://doi.org/10.4149/neo 2016611

[51] ALTANER C, ALTANEROVA V, CIHOVA M, ONDICOVA $\mathrm{K}, \mathrm{RYCHLY} \mathrm{B}$ et al. Complete regression of glioblastoma by mesenchymal stem cells mediated prodrug gene therapy simulating clinical therapeutic scenario. Int J Cancer 2014; 134: 1458-1465. https://doi.org/10.1002/ijc.28455

[52] ZHANG X, PEI Z, CHEN J, JI C, XU J et al. Exosomes for immunoregulation and therapeutic intervention in cancer. J Cancer 2016; 7: 1081-1087. https://doi.org/10.7150/jca.14866

[53] HOSHINO A, COSTA-SILVA, SHEN TL, RODRIGUES G, HASHIMOTO A et al. Tumour exosome integrins determine organotropic metastasis. Nature 2015; 527: 329-335. https:// doi.org/10.1038/nature15756

[54] KAPLAN RN, RIBA RD, ZACHAROULIS S, BRAMLEY AH, VINCENT L et al. EGFR1-positive haematopoietic bone marrow progenitors initiate the pre-metastatic niche. Nature 2005; 438: 820-827. https://doi.org/10.1038/nature04186

[55] RAJKUMAR VS, SHIWEN X, BOSTROM M, LEONI P, MUDDLE J et al. Platelet-derived growth factor-beta receptor activation is essential for fibroblast and pericyte recruitment during cutaneous wound healing. Am J Pathol 2006; 169: 2254-2265. https://doi.org/10.2353/ajpath.2006.060196

[56] ZIMMERMANN JA, MCDEVITT TC. Pre-conditioning mesenchymal stromal cell spheroids for immunomodulatory paracrine factor secretion. Cytotherapy 2014; 16: 331-345. https://doi.org/10.1016/j.jcyt.2013.09.004

[57] UENO T, NAKASHIMA A, DOI S, KAWAMOTO T, HONDA $\mathrm{K}$ et al. Mesenchymal stem cells ameliorate experimental peritoneal fibrosis by suppressing inflammation and inhibiting TGF- $\beta 1$ signaling. Kidney Int 2013; 84: 297-307. https://doi. org/10.1038/ki.2013.81

[58] GU W, HONG X, POTTER C, QU A, XU Q. Mesenchymal stem cells and vascular regeneration. Microcirculation 2017; 24: https://doi.org/10.1111/micc.12324 